\title{
LONG-TERM OUTCOME AFTER BIOLOGIC VERSUS MECHANICAL AORTIC VALVE REPLACEMENT IN 841 PATIENTS
}

David S. Peterseim, MD

Ye-Ying Cen, MA

Srinivas Cheruvu, MHS

Kevin Landolfo, MD

Thomas M. Bashore, MD

James E. Lowe, MD

Walter G. Wolfe, MD

Donald D. Glower, MD
Objective: The purpose of this study was to optimize selection criteria of biologic versus mechanical valve prostheses for aortic valve replacement. Methods: Retrospective analysis was performed for 841 patients undergoing isolated, first-time aortic valve replacement with Carpentier-Edwards $(n=429)$ or St Jude Medical $(n=412)$ prostheses. Results: Patients with Carpentier-Edwards and St Jude Medical valves had similar characteristics. Ten-year survival was similar in each group (Carpentier-Edwards 54\% $\pm 3 \%$ versus St Jude Medical 50\% \pm 6\%; $P$ $=.4)$. Independent predictors of worse survival were older age, renal or lung disease, ejection fraction less than $40 \%$, diabetes, and coronary disease. Carpentier-Edwards versus St Jude Medical prostheses did not affect survival $(P=.4)$. Independent predictors of aortic valve reoperation were younger age and Carpentier-Edwards prosthesis. The linearized rates of thromboembolism were similar, but the linearized rate of hemorrhage was lower with Carpentier-Edwards prostheses $(P<.01)$. Perivalvular leak within 6 months of operation was more likely with $\mathrm{St}$ Jude Medical than with Carpentier-Edwards prostheses $(P=.02)$. Estimated 10-year survival free from valve-related morbidity was better for the St Jude Medical valve in patients aged less than 65 years and was better for the Carpentier-Edwards valve in patients aged more than 65 years. Patients with renal disease, lung disease (in patients more than age 60 years), ejection fraction less than $40 \%$, or coronary disease had a life expectancy of less than 10 years. Conclusions: For first-time, isolated aortic valve replacement, mechanical prostheses should be considered in patients under age 65 years with a life expectancy of at least 10 years. Bioprostheses should be considered in patients over age 65 years or with lung disease (in patients over age 60 years), renal disease, coronary disease, ejection fraction less than $40 \%$, or a life expectancy less than 10 years. (J Thorac Cardiovasc Surg 1999;117:890-7)
$\mathrm{M}^{\mathrm{s}}$ ore than 20 years after the introduction of modern prostheses, the choice of biologic versus mechanical aortic valve prostheses remains difficult. ${ }^{1}$ The clinical decision becomes even more challenging in the presence of coexisting conditions such as advanced age,

From the Departments of Surgery and Medicine, Duke University Medical Center, Durham NC.

This study was funded in part by grants from St Jude Medical, Inc, and Baxter Healthcare Corp.

Received for publication Aug 26, 1998; revisions requested Oct 5, 1998; revisions received Jan 5, 1999; accepted for publication Jan $5,1999$.

Address for reprints: Donald D. Glower, MD; Box 3851, DUMC, Durham, NC 27710.

Copyright (C) 1999 by Mosby, Inc.

$0022-5223 / 99 \$ 8.00+0 \quad \mathbf{1 2 / 1 / 9 7 2 2 9}$ congestive heart failure, coronary artery disease, lung disease, and renal insufficiency. ${ }^{2-5}$ In light of the increasing age and comorbidity of patients who need valve replacement, further knowledge is necessary to determine the most effective treatment. Few large studies exist that compare biologic with mechanical prostheses, and even fewer studies describe the influence of comorbid illness on outcome over a 10-year period, which is often the remaining life-span of these patients. ${ }^{6-11}$ Although any adverse outcome can be costly, the influence of prosthesis type on health care cost remains even less well defined. ${ }^{12}$

The purpose of this study was to examine the determinants of outcome after biologic versus mechanical aortic valve replacement as might be relevant in the selection of a biologic versus a mechanical prosthesis. 
Table I. Preoperative patient characteristics

\begin{tabular}{|c|c|c|c|}
\hline & $\begin{array}{c}C E \\
(n=429)\end{array}$ & $\begin{array}{c}S J \\
(n=412)\end{array}$ & $\mathrm{P}$ value \\
\hline Age $(y)$ & $64 \pm 12$ & $62 \pm 13$ & NS \\
\hline Year of operation & $1984 \pm 5$ & $1990 \pm 3$ & .001 \\
\hline Male $(\%)$ & $307(72)$ & $243(59)$ & .001 \\
\hline Ejection fraction & $50 \pm 15$ & $51 \pm 14$ & NS \\
\hline Atrial fibrillation (\%) & $67(16)$ & $55(13)$ & NS \\
\hline Coronary disease $(\%)$ & $178(41)$ & $169(41)$ & NS \\
\hline Valve size $(\mathrm{mm})$ & $24 \pm 3$ & $23 \pm 3$ & .001 \\
\hline Diabetes $(\%)$ & $45(10)$ & $82(20)$ & .001 \\
\hline Heart failure class & $2.9 \pm 1.0$ & $3.0 \pm 1.0$ & NS \\
\hline Angina class & $2.1 \pm 1.2$ & $2.0 \pm 1.2$ & NS \\
\hline Endocarditis (\%) & $22(5)$ & $8(2)$ & .001 \\
\hline Lung disease $(\%)$ & 82 (19) & $62(15)$ & NS \\
\hline Cerebrovascular disease $(\%)$ & $41(10)$ & $42(10)$ & NS \\
\hline Renal disease $(\%)$ & $28(7)$ & $13(3)$ & .02 \\
\hline Peptic ulcer disease (\%) & $47(11)$ & $44(11)$ & NS \\
\hline Gastrointestinal bleed (\%) & $21(5)$ & $16(4)$ & NS \\
\hline
\end{tabular}

Although many surgeons have agreed that younger and healthier patients should receive mechanical valves and older and sicker patients should receive bioprosthetic valves, a large difference in opinion exists as to the appropriate management of valvular disease in patients between ages 60 and 70 years who often have multiple comorbidities. ${ }^{13}$ This retrospective analysis from one institution investigates whether the outcomes of patients who underwent aortic valve surgery differ with the use of mechanical versus bioprosthetic valves. An algorithm for prosthesis selection in patients with aortic valvular disease is proposed.

\section{Methods}

From 1976 to 1996,1676 patients underwent aortic valve replacement at Duke University Medical Center. To obtain a more homogeneous population, we excluded patients undergoing a concurrent operation for placement of another valve, patients aged less than 18 years, patients receiving valves sized less than $19 \mathrm{~mm}$, and patients with a previous sternotomy. To further improve population homogeneity and to eliminate prostheses that are now less used, we also excluded 489 patients who by surgeon preference received aortic homografts or prostheses used in small numbers. The resultant study population consisted of all 841 patients undergoing isolated, first-time aortic valve replacement with the CarpentierEdwards (CE) standard porcine prosthesis ( $n=429$; model 2625; Baxter Healthcare Corp, Irvine, Calif) or the St Jude Medical (SJ) prosthesis ( $=412$; model A102; St Jude Medical, Inc, St Paul, Minn). As of 1996, follow-up was $100 \%$ complete, that is, all patients were known to be either dead or alive on January 1, 1996. Data were obtained from chart review (18\%), telephone interview (43\%), the National Death Index (33\%), or autopsy $(6 \%)$.

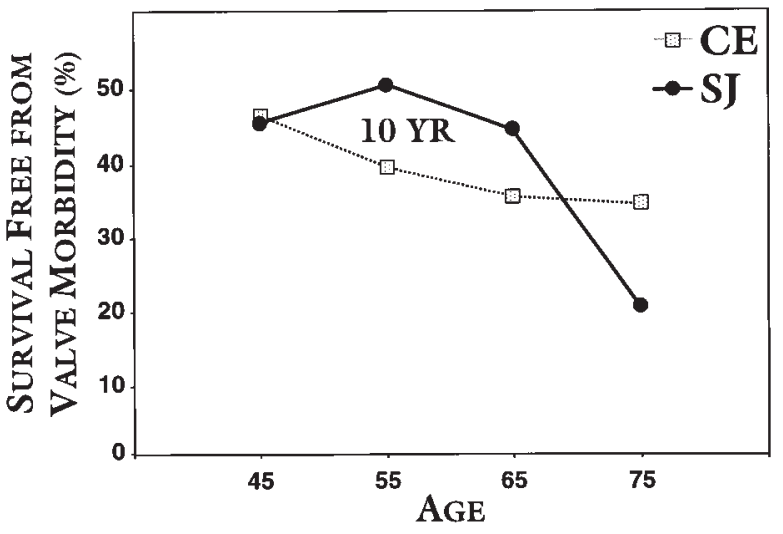

Fig 1. Estimated survival free from valve-related morbidity 10 years after aortic valve replacement with the CE or SJ prostheses as a function of patient age (year).

All aortic valve operations were performed through a median sternotomy with the use of cardiopulmonary bypass and crystalloid or blood cardioplegic solution. Patients with bioprostheses were generally started on long-term aspirin therapy beginning on the first postoperative day. ${ }^{14}$ Patients with mechanical prostheses were started on warfarin sodium (Coumadin) therapy on postoperative day 2, either with or without aspirin therapy. Most patients with a mechanical valve were followed up by their local physicians to maintain an international normalized ratio of 2.0 to 3.0.

Outcomes were defined according to the standard definitions. ${ }^{15}$ Renal disease was identified as a preoperative creatinine level greater than $2.0 \mathrm{mg} / \mathrm{dL}$. Pulmonary disease included any ongoing pulmonary diagnosis requiring treatment. Coronary diameter reduction of $75 \%$ or more was considered to be significant. Endocarditis was defined as a clinical diagnosis of endocarditis. Valve-related morbidity was considered to be any hemorrhage, thromboembolism, aortic valve reoperation, or endocarditis. Perivalvular leak was defined as moderate or severe aortic regurgitation not the result of prosthetic dysfunction.

Data were analyzed with SAS software release 6.12 (SAS Institute, Cary, NC). Continuous data were expressed as mean $\pm \mathrm{SD}$. Comparisons of the 2 groups were made with the Mann-Whitney $U$ test for continuous data not distributed normally. Cox proportional hazards regression model was used in the survival and valve-related outcome analysis. The assumptions of the proportional hazards model were checked graphically. The variables of age and ejection fraction were stratified or converted to binary form to accommodate a nonlinear relationship to risk. Variables were selected for models by a forward and backward stepwise elimination procedure. All univariable factors significant at $P<.10$ were examined. All the statistical analyses were conducted with $\alpha=.05$. To obtain estimates of 10-year survival free of valve-related morbidity in selected age groups where several groups contained fewer than 10 patients, log curve fitting was used ${ }^{16}$ 


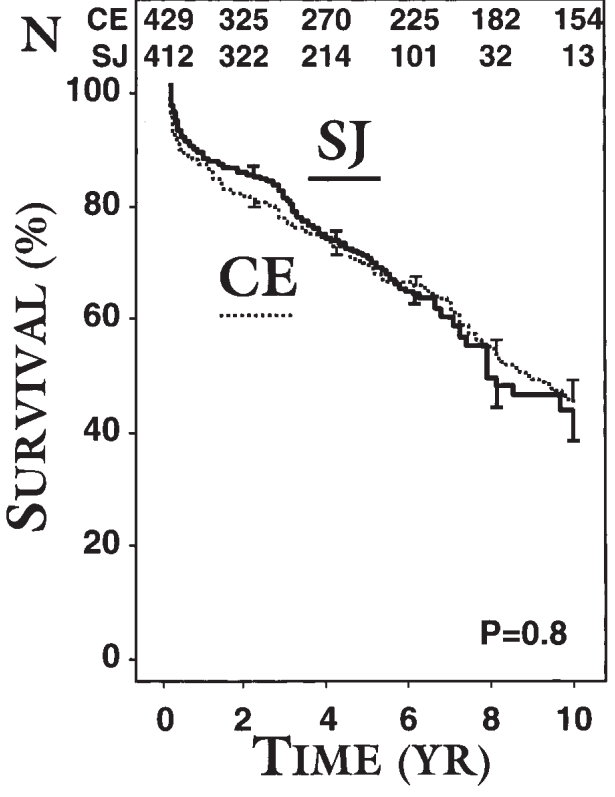

Fig 2. Patient survival after aortic valve replacement with the $\mathrm{CE}$ or SJ prosthesis.

Table II. Predictors of patient survival

\begin{tabular}{lcrccc}
\hline & & \multicolumn{3}{c}{ Hazard } \\
& $\beta$ & $\chi^{2}$ & P value & ratio & $95 \%$ CI \\
\hline Age $\geq 65$ y & $.43 \pm .13$ & 10.2 & .001 & 2.0 & $(1.2,2.0)$ \\
EF < 40\% & $.49 \pm .14$ & 12.7 & .0004 & 2.1 & $(1.2,2.1)$ \\
Coronary disease & $.20 \pm .06$ & 12.0 & .0005 & 1.4 & $(1.1,1.4)$ \\
Lung disease & $.43 \pm .15$ & 8.2 & .004 & 1.5 & $(1.1,2.1)$ \\
Diabetes & $.38 \pm .16$ & 5.4 & .02 & 1.5 & $(1.1,2.0)$ \\
Renal disease & $.80 \pm .23$ & 12.3 & .0004 & 2.2 & $(1.4,3.5)$ \\
\hline
\end{tabular}

CI, Confidence interval.

(Fig 1). Actual (versus actuarial) freedom from events was computed by the method of Grunkemeier and associates. ${ }^{17}$ Kaplan-Meier curves were compared by the log rank test.

\section{Results}

Patients with a CE prosthesis and an SJ prosthesis did not differ significantly in age (Table I). Coronary artery bypass grafting was performed in 152 of 429 patients (35\%) with a CE prosthesis and in 175 of 412 patients $(42 \%)$ with an SJ prosthesis $(P=\mathrm{NS})$. In the SJ prosthesis group, the number of patients undergoing coronary bypass grafting exceeded the number of patients with coronary disease because 6 patients received grafts for vessels with less than $75 \%$ diameter reduction. Patients with a CE prosthesis were more likely to be male and to have an earlier year of operation and larger valve size; they were less likely to have diabetes
Table III. Causes of all deaths

\begin{tabular}{lcc}
\hline & $C E(n)$ & $S J(n)$ \\
\hline Noncardiac (\%) & $45(22)$ & $17(16)$ \\
Congestive heart failure (\%) & $42(22)$ & $19(18)$ \\
Other cardiac (\%) & $29(14)$ & $12(11)$ \\
Infection (\%) & $14(7)$ & $7(7)$ \\
Myocardial infarction (\%) & $12(6)$ & $9(9)$ \\
Stroke (\%) & $4(2)$ & $4(4)$ \\
Sudden (\%) & $5(2)$ & $1(1)$ \\
Hemorrhage (\%) & $1(0)$ & $2(2)$ \\
Structural valvular deterioration (\%) & $1(0)$ & $0(0)$ \\
Unknown (\%) & $54(26)$ & $34(32)$ \\
Total & 207 & 105 \\
\hline
\end{tabular}

or renal disease, but more likely to have endocarditis. However, there was no significant difference in ejection fraction, coronary disease, angina, or heart failure.

Thirty-day survival. The absolute 30 -day mortality rate was 35 of 429 patients $(8 \% \pm 1 \%)$ for patients with a CE prosthesis and 15 of 412 patients $(4 \% \pm 1 \%)$ for patients with an SJ prosthesis $(P<.01)$. By logistic regression, independent predictors of 30-day mortality were earlier year of operation $\left(\chi^{2}=8.2 ; P=.004\right)$ and concurrent coronary bypass grafting $\left(\chi^{2}=6.3 ; P=.01\right)$. Valve make (CE versus SJ prosthesis ) was not an independent predictor of 30-day mortality $\left(\chi^{2}=2.6 ; P=\right.$ .10). Thus the higher 30-day mortality rate for patients with a $\mathrm{CE}$ versus an SJ prosthesis was largely attributable to the earlier year of operation for patients with a CE versus an SJ prosthesis and the improvement in operative mortality rate from 1976 to 1996.

Late survival. After aortic valve replacement, there was no significant difference in survival of patients receiving a $\mathrm{CE}$ versus an $\mathrm{SJ}$ prosthesis $(54 \% \pm 3 \%$ vs $50 \% \pm 6 \%$ at 10 years; $P=.4$; Fig 2). By Cox model analysis, independent multivariable factors predicting worse survival included older age, renal disease, ejection fraction less than $40 \%$, lung disease, coronary artery disease, and diabetes (Table II). A CE versus an SJ make of valve $(P=.4)$ and year of operation $(P=.5)$ were not significant predictors of late survival by multivariable analysis. Causes of all deaths (early and late) were not significantly different $(P=.8)$ between patients with a CE prosthesis and patients with an SJ prosthesis (Table III).

Valve-related complications. At discharge, 4 of 377 patients (1\%) with a CE prosthesis and 364 of 379 patients $(96 \%)$ with an SJ prosthesis were receiving warfarin therapy. At last follow-up for living patients, 12 of 171 patients (7\%) with a CE prosthesis and 219 of 225 patients (97\%) with an SJ prosthesis were receiving warfarin therapy. Discharge medications were unknown 


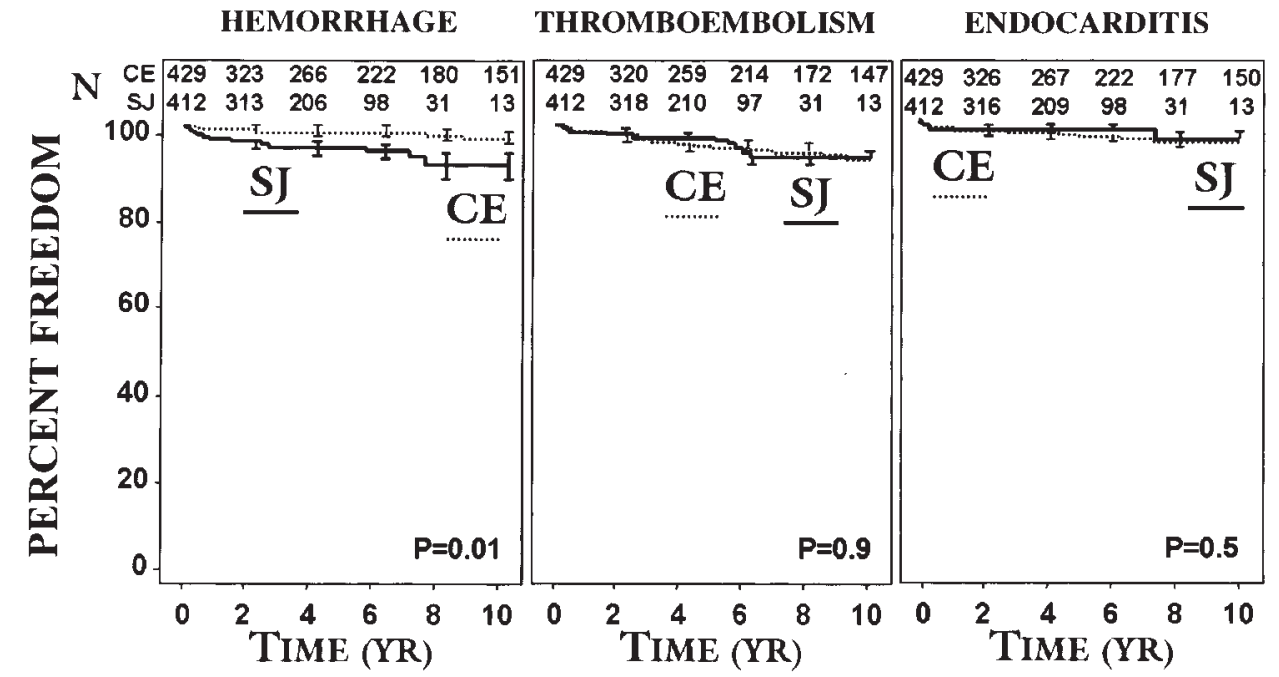

Fig 3. Freedom from hemorrhage, thromboembolism, and endocarditis after aortic valve replacement with the CE or SJ prosthesis.

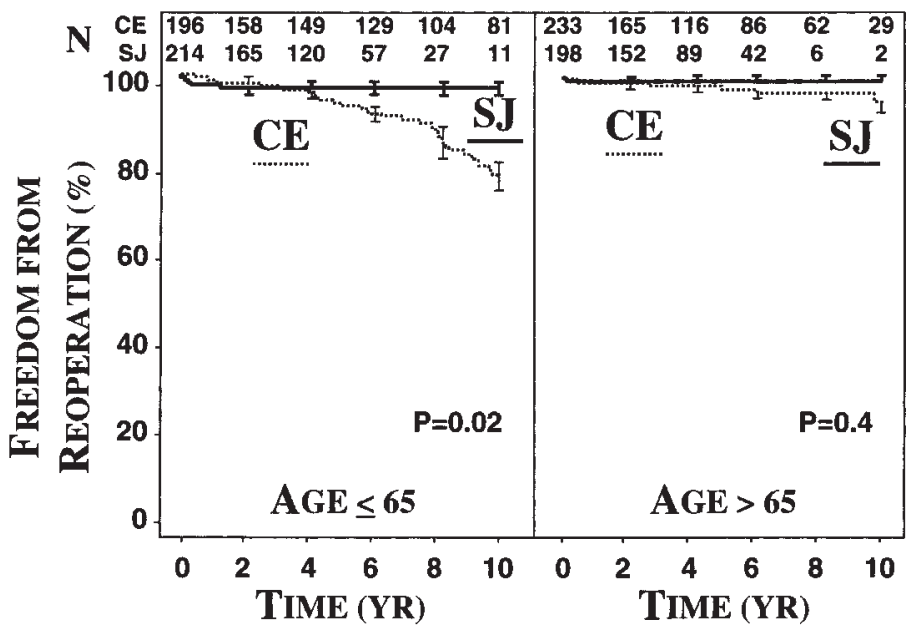

Fig 4. Freedom from aortic valve reoperation after aortic valve replacement with the CE or SJ prostheses in patients aged 65 years or less (left panel) or 65 years or more (right panel).

in 13 of 390 patients (3\%) with a CE prosthesis and in 15 of 394 patients (4\%) with an SJ prosthesis; medications at last follow-up were unknown in 51 of 222 patients $(23 \%)$ with a CE prosthesis and in 82 of 307 patients $(27 \%)$ with an SJ prosthesis. Ten-year freedom from hemorrhage was higher for patients with a $\mathrm{CE}$ prosthesis than for patients with an SJ prosthesis $(97 \%$ $\pm 1 \%$ vs $91 \% \pm 3 \% ; P=.01$; Fig 3 ). By Cox model analysis, the only variable predictive of hemorrhage was SJ valve make $(P=.003)$; patient age did not significantly affect hemorrhage. The linearized rate of hemorrhage was significantly lower for patients with a $\mathrm{CE}$ prosthesis than for patients with an SJ prosthesis $(0.3 \%$ $\pm 0.1 \% /$ pt-y versus $1.2 \% \pm 0.3 \% / p t-y ; P=.001)$. Tenyear freedom from thromboembolism was not significantly different for patients with a CE prosthesis versus patients with an SJ prosthesis $(93 \% \pm 2 \%$ vs $94 \% \pm 2 \%$; $P=.9$; Fig 3). By Cox model analysis, no variables including age were identified to be predictive of thromboembolism. The linearized rates of thromboembolism were not significantly different for patients with a $\mathrm{CE}$ prosthesis versus patients with an SJ prosthesis $(0.7 \% \pm$ $0.2 \% / \mathrm{pt}-\mathrm{y}$ vs $1.0 \% \pm 0.3 \% / \mathrm{pt}-\mathrm{y} ; P=.3$ ).

Perivalvular leak was noted in 21 of 429 patients $(5 \%)$ with a CE prosthesis and 18 of 412 patients (4\%) with an SJ prosthesis $(P=.7)$. Perivalvular leak was treated 


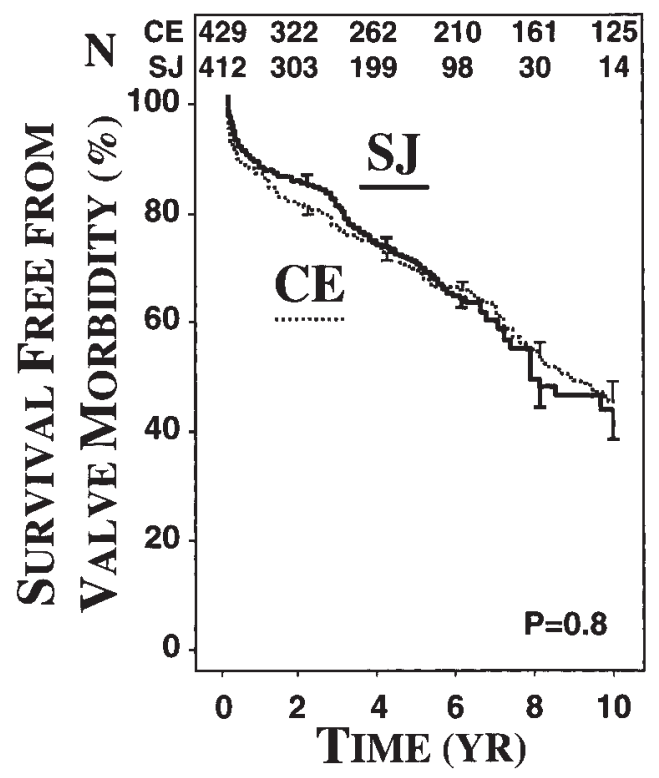

Fig 5. Survival free from valve-related morbidity after aortic valve replacement with the $\mathrm{CE}$ or SJ prostheses.

with reoperation in 12 of 21 patients (57\%) with a CE prosthesis versus 6 of 18 patients (33\%) with an SJ prosthesis $(P>.1)$. Ten-year freedom from perivalvular leak was not significantly different for patients with a CE prosthesis versus patients with an SJ prosthesis $(92 \% \pm 2 \%$ vs $91 \% \pm 3 \% ; P=.3)$. Perivalvular leak was significantly more likely to be noted in the first 6 months after operation with an $\mathrm{SJ}$ versus a $\mathrm{CE}$ prostheses $(8$ of 412 patients [1.9\%] vs 1 of 429 patients $[0.2 \%] ; P=.02)$. The linearized rate of perivalvular leak was $0.7 \% \pm 0.1 \% / \mathrm{pt}-\mathrm{y}$ for a CE prosthesis versus $1.0 \%$ $\pm 0.2 \% / \mathrm{pt}-\mathrm{y}$ for an SJ prosthesis $(P=.2)$.

Ten-year freedom from endocarditis was not significantly different between patients with a CE prosthesis and patients with an SJ prosthesis $(96 \% \pm 1 \%$ vs $97 \%$ $\pm 1 \%$; $P=.5$; Fig 3 ). By Cox model analysis, the only variable predictive of late endocarditis was preoperative endocarditis $\left(\beta=2.3 \pm .5 ; \chi^{2}=20.5 ; P=.0001\right)$, and age did not significantly affect late endocarditis. The linearized rates of endocarditis were $0.4 \% \pm$ $0.1 \% /$ pt-y for patients with a CE prosthesis and $0.4 \% \pm$ $0.1 \% /$ pt-y for patients with an SJ prosthesis $(P=.9)$.

Ten-year freedom from aortic valve reoperation was significantly better for patients with an SJ prosthesis $(98 \% \pm 1 \%$ vs $83 \% \pm 3 \% ; P=.02)$. By Cox model analysis, the only independent variables predictive of aortic valve reoperation were $\mathrm{CE}$ valve make $(\beta=-1.0$ $\left.\pm .4 ; \chi^{2}=6.6 ; P=.01\right)$ and younger patient age $(\beta=$ $\left.-.044 \pm .009 ; \chi^{2}=25.2 ; P=.0001\right)$. For patients over
Table IV. Patient groups with life expectancy of less than 10 years

\begin{tabular}{|c|c|c|}
\hline & $\begin{array}{c}\text { Ten-year } \\
\text { survival }(\%)\end{array}$ & $\begin{array}{l}\text { Actual } 10 \text {-year } \\
\text { freedom from } \\
\text { reoperation on } \\
\text { CE aortic valve (\%) }\end{array}$ \\
\hline Renal disease, any age & $27 \pm 8$ & $100 \pm 0$ \\
\hline $\begin{array}{l}\text { Lung disease (patient older than } \\
60 \mathrm{y} \text { ) }\end{array}$ & $30 \pm 6$ & $96 \pm 2$ \\
\hline Ejection fraction $<40 \%$, any age & $35 \pm 6$ & $95 \pm 2$ \\
\hline Coronary artery disease, any age & $35 \pm 5$ & $98 \pm 0.8$ \\
\hline Age $>65$ y & $41 \pm 4$ & $98 \pm 0.7$ \\
\hline
\end{tabular}

65 years old, valve make did not affect aortic valve reoperation $(P=.4$, Fig 4$)$. For patients aged 65 years and younger, freedom from reoperation was significantly better for an $\mathrm{SJ}$ versus a CE prosthesis $(P=.02$; Fig 4). After reoperation, the 30-day mortality rate was 4 of $63(6 \%)$ for all patients and 1 of $9(11 \%)$ in all patients with coronary bypass grafting with the original aortic valve operation.

Survival free from valve-related morbidity. After an examination of all 841 study patients, there was no significant difference in survival free from valve-related morbidity (defined earlier) between patients receiving a $\mathrm{CE}$ versus an SJ prostheses $(43 \% \pm 3 \%$ vs $41 \% \pm$ $5 \% ; P=.8$; Fig 5). By Cox model analysis, independent multivariable factors predicting worse survival free from valve-related morbidity were ejection fraction less than $40 \%\left(\chi^{2}=11.9 ; P=.0005\right)$, renal disease $\left(\chi^{2}=10.1 ; P=.002\right)$, diabetes $\left(\chi^{2}=8.2 ; P=.004\right)$, and coronary artery disease $\left(\chi^{2}=6.5 ; P=.01\right)$. For the entire pool of 841 patients, make of valve (CE vs SJ) and year of operation were not significant predictors of survival free from valve-related morbidity.

Because age was a determinant of both survival and reoperation, survival free from valve-related morbidity was examined as a function of patient age. At 10 years after operation, survival free from valve-related morbidity was better with $\mathrm{CE}$ valves in patients over 65 years old and was better with SJ valves in patients under 65 years old (Fig 1).

For patients not surviving 10 years, $\mathrm{CE}$ bioprostheses would be preferable because of the absence of anticoagulant-related hemorrhage and because of the rarity of reoperation within 10 years in these patients. Several groups of patients with a life expectancy less than 10 years (thus favoring bioprostheses) included patients over 65 years old, patients with lung disease who are under age 60 years, and patients at any age with renal disease, ejection fraction less than $40 \%$, or coronary 
Table V. Linearized rates of complications

\begin{tabular}{|c|c|c|c|c|c|c|c|c|c|c|}
\hline \multirow[b]{2}{*}{ Complication } & \multicolumn{2}{|c|}{$\begin{array}{c}\text { Peterseim, } \\
1999 \\
\text { (nonrandomized) }\end{array}$} & \multicolumn{2}{|c|}{$\begin{array}{c}\text { Holper et al, }{ }^{9} \\
1995 \\
\text { (nonrandomized) }\end{array}$} & \multicolumn{2}{|c|}{$\begin{array}{c}\text { Myken et al, }{ }^{11} \\
1995 \\
\text { (nonrandomized) }\end{array}$} & \multicolumn{2}{|c|}{$\begin{array}{c}\text { Hammermeister et al, }{ }^{8} \\
1993 \\
\text { (randomized) }\end{array}$} & \multicolumn{2}{|c|}{$\begin{array}{c}\text { Bloomfield et al, } \\
1991 \\
\text { (randomized) }\end{array}$} \\
\hline & $\begin{array}{c}\text { Bio } \\
(n=429)\end{array}$ & $\begin{array}{c}\text { Mech } \\
(n=412)\end{array}$ & $\begin{array}{c}\text { Bio } \\
(n=326)\end{array}$ & $\begin{array}{c}\text { Mech } \\
(n=250)\end{array}$ & $\begin{array}{c}\text { Bio } \\
(n=100)\end{array}$ & $\begin{array}{c}\text { Mech } \\
(n=100)\end{array}$ & $\begin{array}{c}\text { Bio } \\
(n=196)\end{array}$ & $\begin{array}{c}\text { Mech } \\
(n=198)\end{array}$ & $\begin{array}{c}\text { Bio } \\
(n=102)\end{array}$ & $\begin{array}{c}\text { Mech } \\
(n=109)\end{array}$ \\
\hline Hemorrhage (\%/pt-y) & 0.3 & 1.2 & 0.94 & 3.0 & 0.1 & 2.3 & 2.2 & 3.9 & 0.81 & 2.7 \\
\hline Thromboembolism & 0.7 & 1.0 & 1.29 & 1.32 & 0.6 & 1.2 & 1.4 & 1.5 & 1.9 & 0.96 \\
\hline Leak (\%/pt-y) & 0.7 & 1.0 & 0.14 & 0.24 & & & 0.18 & 0.36 & & \\
\hline Endocarditis (\%/pt-y) & 0.4 & 0.4 & 0.14 & 0.36 & 0.6 & 0.5 & 0.73 & 0.64 & 0.18 & 0.4 \\
\hline
\end{tabular}

disease. Even in patients under 55 years old, the presence of coronary disease produced a 10-year survival of $35 \% \pm 13 \%$ for patients with a CE prosthesis and patients with an SJ prosthesis combined. For patients in any of these groups who received a CE bioprosthesis, the actual 10-year freedom from aortic valve reoperation $^{15}$ was at least $95 \%$ (Table IV).

\section{Discussion}

Only a few large studies have compared outcomes between biologic and mechanical valve replacement; the results of the most recent studies are summarized in Table V. The current study confirmed a greater incidence of hemorrhage with mechanical versus biologic valves. $^{8-11,18}$ The hemorrhage rate with mechanical prostheses in this study $(1.2 \% \pm 0.3 \% / \mathrm{pt}-\mathrm{y})$ was somewhat less than the $2 \% / \mathrm{pt}-\mathrm{y}$ reported in most series. ${ }^{8-11,18}$ This difference may result from the low-risk population (first-time isolated aortic valve replacement) and the recent time frame in this study where anticoagulation was maintained at lower levels than in earlier years. The thromboembolic rate of this study is comparable with other reports for both biologic and mechanical prostheses..$^{8-11,18}$ This study confirms the higher incidence of aortic valve reoperation in patients receiving a bioprosthesis and in younger patients. ${ }^{19}$

This retrospective analysis of 841 patients differs from previous studies in several respects. No recent study compared the modern CE and SJ prostheses, ${ }^{20,21}$ and the current study is the third largest study comparing biologic and mechanical aortic valves to date. ${ }^{13,21}$ In the two larger series, both biologic and mechanical patient groups included several makes of prostheses, which may differ in durability, flow characteristics, or thrombogenicity. ${ }^{13.21}$ Only the Cleveland Clinic study with multiple valve makes used multivariable analysis to examine the effects of comorbidity on survival after biologic versus mechanical aortic valve replacement. The Cleveland Clinic study confirmed that age and mechanical prostheses impaired event-free survival, but only in patients over age 60 years or not receiving anticoagulation over age 40 years. $^{21}$

The current study is the first to provide numeric data supporting guidelines to select biologic versus mechanical devices based on patient comorbidity other than age (Table IV). The current study provides data that support a specific age (65 years) over which survival free from valve-related events is better with biologic valves, ${ }^{22,23}$ although outcome tended to be better with mechanical valves in younger patients (Table IV; Fig 1). Previous studies not examining comorbidities other than coronary disease have placed the cutoff for biologic versus mechanical prostheses at 65 to 70 years. ${ }^{22,23}$ Patient selection bias (eg, patients with biologic valves having significantly less coronary disease) may explain why the Cleveland Clinic study showed better event-free survival with bioprostheses in patients over age 40 years. $^{21}$

The significantly higher incidence of early perivalvular leak rate in the SJ group has not been previously reported. Explanations for this finding may include differences in sewing ring width and shape between SJ and CE prostheses, along with the tendency to use SJ prostheses in smaller aortic roots where valve seating may be more difficult (Table I). SJ and other valve makes are now available with large sewing rings that were not used in this study.

The nonrandomized, retrospective nature of this study limits the findings. The major bias between the $\mathrm{CE}$ and SJ groups was the earlier year of operation and the resultant higher 30-day mortality in patients with a $\mathrm{CE}$ prosthesis. One possible effect of overestimating early deaths after $\mathrm{CE}$ aortic valve replacement may be to underestimate 10-year survival free from valve-related morbidity in patients with a CE prosthesis. In turn, this bias may mean that the CE and SJ curves in Fig 1 actually should cross at age 65 years instead of age 70 years. These data therefore suggest that the age at 
which CE valves become advantageous is 65 years in this patient population.

An additional shortcoming of this study is the limited follow-up in the SJ group after 10 years, at which time differences between biologic and mechanical valves may be magnified by increased reoperation for structural deterioration of the bioprostheses. Fifteenyear data await further study; however, the conclusions of this study are based on 10-year results and are unlikely to be changed by data from the small number of patients surviving 15 years or more. Although the current study was limited to first-time isolated aortic valve procedures (with or without coronary bypass grafting), the results could well be different in patients with a previous cardiac operation or multiple valve operations. ${ }^{10}$ Although this study is among the largest studies to date, the small patient numbers in some subgroups may have limited the ability to define ages where life expectancy could exceed 10 years and where results might therefore favor mechanical prostheses (eg, young patients with coronary disease; Table IV). In addition, the presence of previous coronary grafts in a young patient undergoing reoperation for a failed bioprosthesis could increase late mortality rates, although the reoperative mortality was a modest $11 \%$ for patients of all ages with previous coronary bypass grafts in the current study. The reported mortality rate for aortic valve operation has been $14 \%$ after previous coronary bypass ${ }^{24}$ and as low as $8 \%$ after previous aortic valve replacement. ${ }^{25}$

The current study evaluated a second generation porcine bioprosthesis that has been partly displaced by pericardial bioprostheses (models 2700 and 2800; Baxter Healthcare Corp). Yet, the study is still relevant because pericardial and porcine aortic prostheses have similar durability and performance characteristics. ${ }^{26-29}$ The SJ valve (model A102) used in this study continues to be widely used..$^{30,31}$

Choice of an aortic bioprosthesis versus mechanical prosthesis should be individualized on the basis of the patient's ability to take warfarin and the patient's age and life expectancy. This choice primarily is one of increased likelihood of reoperation with bioprostheses versus increased likelihood of hemorrhage with mechanical prostheses. The relatively low 10-year survival of 50\% to 54\% and the high frequency of cardiac deaths (Table III) suggest that other factors, such as optimal timing of operation, may be more important to survival than prosthesis selection. The results of this study support the general philosophy that older, sicker patients tend to benefit more from bioprostheses and that younger, healthier patients should receive mechanical prostheses. Otherwise, patients who are unable to reliably take warfarin or who have medical illnesses precluding anticoagulation should receive a bioprosthesis.

The current study provides data that suggest age cutoff points for selecting biologic versus mechanical valves in different patient subgroups (Table IV; Fig 1). Patients with an expected survival of less than 10 years (more than 65 years old, renal disease, lung disease, patients who are more than 60 years old), ejection fraction of less than $40 \%$, or coronary disease (Table IV; Fig 1) would be reasonable candidates for aortic bioprostheses to avoid anticoagulation with an extremely low likelihood of aortic valve reoperation (Table IV). Results tend to favor mechanical aortic valves in patients under age 65 years with a life expectancy of at least 10 years (Fig 1). Specific subsets of patients undergoing multiple valve operation or repeat cardiac operation merit further investigation. ${ }^{10}$

\section{REFERENCES}

1. Treasure T. Which prosthetic valve should we choose? Curr Opin Cardiol 1995;10:144-9.

2. Burr LH, Jamieson WRE, Munro AI, Miyagshima RT, Germann E. Porcine bioprostheses in the elderly: clinical performance by age groups and valve position. Ann Thorac Surg 1995;60:S264-9.

3. Hwang MH, Burchfiel CM, Sethi GK, Oprian C, Grover FL, Henderson WG, et al. Comparison of the causes of late death following aortic and mitral valve replacement: VA co-operative study on valvular heart disease. J Heart Valve Dis 1994;3:17-24.

4. Jamieson WRE. Modern cardiac valve devices-bioprostheses and mechanical prostheses: state of the art. J Card Surg 1993;8: 89-98.

5. Milano AD, Bortolotti U, Mazzucco A, Guerra F, Magni A, Gallucci V. Aortic valve replacement with the Hancock Standard, Bjork-Shiley, and Lillehei-Kaster prostheses: a comparison based on follow-up from 1 to 15 years. J Thorac Cardiovasc Surg 1989; 98:37-47.

6. Davis EA, Greene PS, Cameron DE, Gott VL, Laschinger JC, Stuart RS, et al. Bioprosthetic versus mechanical prostheses for aortic valve replacement in the elderly. Circulation 1996;94 (Suppl):II121-5.

7. Fradet GJ, Jamieson WRE, Abel JG, Lichtenstein SV, Miyagishima RT, Ling H, et al. Clinical performance of biological and mechanical prostheses. Ann Thorac Surg 1995;60:S4538.

8. Hammermeister KE, Sethi GK, Henderson WG, Oprian C, Kim T, Rahimtoola S. A comparison of outcomes in men 11 years after heart-valve replacement with a mechanical or bioprosthesis. N Engl J Med 1993;328:1289-96.

9. Holper K, Wottke M, Lewe T, Baumer L, Meisner H, Paek SU, et al. Bioprosthetic and mechanical valves in the elderly: benefits and risks. Ann Thorac Surg 1995;60:S443-6.

10. Munro AI, Jamieson WRE, Burr LH, Ling H, Miyagishima RT, Germann E. Comparison of porcine bioprostheses and mechanical prostheses in multiple valve replacement operations. Ann Thorac Surg 1995;60:S459-62. 
11. Myken PSU, Caidahl K, Larsson P, Larsson S, Wallentin I, Berggren HE. Mechanical versus biological valve prosthesis: a ten-year comparison regarding function and quality of life. Ann Thorac Surg 1995;60:S447-52.

12. Caro JJ, Migliaccio-Walle K, O'Brien JA. The cost of treating heart valve related complications. J Heart Valve Dis 1996;5:122-7.

13. Asimakopoulos G, Edwards MB, Taylor KM. Aortic valve replacement in patients 80 years of age and older: survival and cause of death based on 1100 cases - collective results from the UK Heart Valve Registry. Circulation 1997;96:3403-8.

14. Blair KL, Hatton AC, White WD, Smith LR, Lowe JE, Wolfe $\mathrm{WG}$, et al. Comparison of anticoagulation regimens following Carpentier-Edwards aortic or mitral valve replacement. Circulation 1994;90(Suppl):II214-9.

15. Edmunds LH Jr, Clark RE, Cohn LH, Grunkemeier GL, Miller DC, Weisel RD. Guidelines for reporting morbidity and mortality after cardiac valvular operations. J Thorac Cardiovasc Surg 1996;112:708-11.

16. Hintze JL. Number cruncher statistical system: version 5.5: survival analysis. Kaysville [UT]. Dr Jerry L. Hintze; 1988. p. 20-6.

17. Grunkemeier GL, Jamieson WRE, Miller DC, Starr A. Actuarial versus actual risk of porcine structural valve deterioration. J Thorac Cardiovasc Surg 1994;108:709-18.

18. Bloomfield P, Wheatley DJ, Prescott RJ, Miller HC. Twelve-year comparison of a Björk-Shiley mechanical heart valve with porcine bioprostheses. N Engl J Med 1991;324:573-9.

19. Glower DD, White WD, Hatton AC, Smith LR, Young WG, Wolfe WG, et al. Determinants of reoperation after 960 valve replacements with Carpentier-Edwards prostheses. J Thorac Cardiovasc Surg 1994;107:381-93.

20. Douglas PS, Hirschfield JW Jr, Edie RN, Harken AH, Stephenson LW, Edmunds LH Jr. Clinical comparison of St Jude and porcine aortic valve prostheses. Circulation 1985;72(Suppl):II135-9.

21. Lytle BW, Cosgrove DM, Taylor PC, Goormastic M, Stewart RW, Golding LAR, et al. Primary isolated aortic valve replacement: early and late results. J Thorac Cardiovasc Surg 1898;97:675-94.

22. Jamieson WRE, Munro AI, Burr LH, Germann E, Miyagishima RT, Ling $H$. Influence of coronary artery bypass and age on clinical performance after aortic and mitral valve replacement with biological and mechanical prostheses. Circulation 1995;92 (Suppl):II101-6.

23. Kobayashi Y, Eishi K, Nagata S, Nakano K, Sasako Y, Kobayashi $\mathrm{J}$, et al. Choice of replacement valve in the elderly. J Heart Valve Dis 1997;6:404-9.

24. Fighali SF, Avendano A, MacArthur AE, Lee VV, Hernandez C, Siero V, et al. Early and late mortality of patients undergoing aortic valve replacement after previous coronary artery bypass graft surgery. Circulation 1995;92(Suppl):II163-8.

25. Akins CW, Buckley MJ, Daggett WM, Hilgenberg AD, Vlahakes
GJ, Torchiana DF, et al. Risk of reoperative valve replacement for failed mitral and aortic bioprostheses. Ann Thorac Surg 1998; 65:1545-51.

26. Aupart MR, Sirinelli AL, Diemont FF, Meurisse YA, Dreyfus $\mathrm{XB}$, Marchand MA. The last generation of pericardial valves in the aortic position: ten-year follow-up in 589 patients. Ann Thorac Surg 1996;61:615-20.

27. Frater RW, Furlong P, Cosgrove DM, Okies JE, Colburn LQ, Katz AS, et al. Long-term durability and patient functional status of the Carpentier-Edwards Perimount pericardial bioprosthesis in the aortic position. J Heart Valve Dis 1998;7:48-53.

28. Jamieson WRE, Burr LH, Tyers GFO, Munro AI. CarpentierEdwards standard and supra-annular porcine bioprostheses: 10 year comparison of structural valve deterioration. J Heart Valve Dis 1994;3:59-65.

29. Reichenspurner H, Weinhold C, Nollert G, Kaulbach HG, Vetter $\mathrm{HO}$ Boehm DH, et al. Comparison of porcine biological valves with pericardial valves: a 12-year clinical experience with 1123 bio-prostheses. Thorac Cardiovasc Surg 1995;43:19-26.

30. Emery RW, Arom KV, Nicoloff DM. Utilization of the St Jude Medical prosthesis in the aortic position. Semin Thorac Cardiovasc Surg 1996;8:231-6.

31. Fernandez J, Laub GW, Adkins MS, Anderson WA, Chen C, Bailey BM, et al. Early and late-phase events after valve replacement with the St Jude Medical prosthesis in 1200 patients. J Thorac Cardiovasc Surg 1994;107:394-406.

\section{Appendix}

Preoperative variables included in Cox proportional hazards models:

Valve type

Age older than 65 years

Sex

Ejection fraction less than $40 \%$

Operation year

New York Heart Association heart failure class IV

Diabetes

Renal failure

Liver disease

Lung disease

Atrial fibrillation

Aortic regurgitation

Number of diseased coronary vessels

Peptic ulcer disease

Previous gastrointestinal hemorrhage

Endocarditis within 6 months 